\title{
Long non-coding RNA growth arrest-specific transcript 5 is involved in ovarian cancer cell apoptosis through the mitochondria-mediated apoptosis pathway
}

\author{
JIAYIN GAO $^{1 *}$, MEIMEI LIU $^{1 *}$, YITING ZOU $^{1}$, MIN MAO $^{2}$, TINGTING SHEN ${ }^{2}$, CHEN ZHANG $^{2}$, \\ SHASHA SONG ${ }^{2}$, MEILING SUN $^{3}$, SONG ZHANG $^{4}$, BEIDI WANG $^{1}$, DALING ZHU $^{2}$ and PEILING LI ${ }^{1}$ \\ ${ }^{1}$ Department of Obstetrics and Gynecology, The Second Affiliated Hospital of Harbin Medical University, Harbin; \\ ${ }^{2}$ Department of Biopharmaceutical Sciences, College of Pharmacy, Harbin Medical University (Daqing), \\ Daqing; ${ }^{3}$ Department of Nursing, The Second Affiliated Hospital of Harbin Medical University, Harbin; \\ ${ }^{4}$ Department of Medical Service, The First Affiliated Hospital of Harbin Medical University, Harbin, P.R. China
}

Received July 5, 2015; Accepted August 18, 2015

DOI: $10.3892 / o r .2015 .4318$

\begin{abstract}
The present study investigated the underlying role of growth arrest-specific transcript 5 (GAS5) in epithelial ovarian cancer (EOC), which is the main cause of death in women with malignant tumor of the genital system. In vivo GAS5 expression in $60 \mathrm{EOC}$ specimens was evaluated by quantitative reverse transcription (qRT)-PCR, which was used to study the differences of GAS5 expression between EOC tissues and normal ovarian epithelium. In vitro GAS5 overexpression was applied to discover the biological functions in EOC cell lines. 3-[4,5-Dimethylthiazol-2-yl]-2,5-diphenyl-tetrazolium bromide and colony formation assays were employed to investigate the effect on proliferation. The function of apoptosis was assessed by flow cytometry, terminal deoxynucleotidyl transferase dUTP nick-end labeling, and JC-1 probe staining, and migration and invasion were detected by Transwell assay. The data show that no significant differences of GAS5 expression were observed between normal ovarian epithelium and benign epithelial lesions; however, GAS5 expression was lower in EOC tissues compared with normal ovarian epithelial tissues (6.44-fold), which was closely related to lymph node metastasis $(\mathrm{P}=0.025)$ and tumor node metastasis stage
\end{abstract}

Correspondence to: Professor Peiling Li, Department of Obstetrics and Gynecology, The Second Affiliated Hospital of Harbin Medical University, Xuefu Road, Harbin 150081, P.R. China

E-mail: peiley@126.com

Professor Daling Zhu, Department of Biopharmaceutical Sciences, College of Pharmacy, Harbin Medical University (Daqing), Xinyang Road, Daqing 163319, P.R. China

E-mail: dalingz@yahoo.com

*Contributed equally

Key words: long non-coding RNA, epithelial ovarian cancer, GAS5, apoptosis, mitochondrion
$(\mathrm{P}=0.035)$. Moreover, exogenous GAS5-inhibited proliferation promoted apoptosis and decreased migration and invasion in ovarian cancer cells. Finally, through mitochondrial potential and western blot analyses, GAS5 could disrupt mitochondrial membrane potential and promote BAX, BAK, cleaved-caspase 3 and cleaved-caspase 9 expression. Taken together, the findings of the present study revealed that GAS5 is downregulated in EOC specimens, and GAS5 inhibits EOC cell proliferation, migration and invasion, and promotes cell apoptosis. GAS5 can serve as a novel therapeutic target in patients with EOC.

\section{Introduction}

Ovarian cancer is a genetic disease, and the main cause of death of women with a malignant tumor of the genital system, showing a high morbidity rate in developing countries. It is still the fifth major cause of death in women with cancer, in spite of rapid progress in diagnosis and treatment of ovarian cancer (1). Of all ovarian carcinoma cases, epithelial ovarian cancer (EOC) accounts for $90 \%$ of morbidity (2). Moreover, EOC can spread to peritoneal cavity via peritoneal fluid, contributing to the inefficiency of surgery and chemotherapy treatment. Most patients die of recurrence. Previous findings confirmed that the dysfunctional molecular mechanism targeted EOC, for instance, Kras, Brca1/2, Tp53, Rb and PTEN (3-5). A better understanding of the mechanisms involved in EOC and more effective therapeutic approaches are urgently needed.

Long non-coding RNA (lncRNA) does not translate into proteins and is longer than 200 nucleotides (6). Increasingly lncRNAs are emerging as important regulators of tumor initiation and progression (7). The tempting potential in most of the lncRNAs have stimulated keen interests, particularly the cancer complexity. More recently, CCAT1-L has been shown to play a role in MYC transcriptional regulation and to promote a long-range chromatin looping (8-10). MALAT1 has been reported to promote cancer metastasis (11) or resist rapid RNA decay (12-14). The findings 
indicate that lncRNAs may act as important regulators in tumorigenesis.

The present study describes the lncRNA growth arrestspecific transcript 5 (GAS5), which is alternatively spliced and is transcribed from locus 1q25.1 (15). GAS5 regulates a valuable biological function since it is a multiple-snoRNAhost gene (16). Functionally, GAS5 competes with the glucocorticoid response elements in the genome for binding to these receptors and promotes cells apoptosis (17), which were originally identified in leukemic and NIH3T3 cells (18). Intriguingly, the inhibition of mammalian target of rapamycin (mTOR) pathway depends on GAS5 (19), which negatively regulates miR-21 possibly through the RNA-induced silencing complex (20). Additionally, it was shown that GAS5 is downregulated in some cancer cell lines and tissues (21-24). For example, GAS5 inhibits malignant pleural mesothelioma (MPM) cell growth by inhibiting hedgehog and PI3K/mTOR signal pathway in MPM (23). GAS5 as a tumor suppressor in non-small cell lung cancer (NSCLC) mediated by the p53-independent and p53-dependent pathways (25). GAS5 is able to inhibit E2F1 and cyclin D1, and thus leads to decreased gastric cancer cell proliferation (24). However, the role of GAS5 in ovarian cancer has not been previously reported.

The fundamental mechanisms of GAS5 on tumorigenesis remain largely unknown, although GAS5 has been indicated to take part in suppression on malignant tumors. The potential mechanisms can be related to the fact that GAS5 regulates nonsense-mediated RNA decay pathway $(19,26)$ or downregulates c-Myc (27). These findings provide strong evidence that GAS5 plays an important role in guiding the cell fate toward apoptosis. It is well known that apoptosis is a regulated cell death process and plays a significant role in most of the physiological processes. Apoptosis can be caused by the extrinsic or intrinsic pathway; the former occurs through triggering the transmembrane death receptors, while, the latter is initiated from intracellular developmental cues or cell stress $(28,29)$. In the intrinsic apoptotic pathway, mitochondria is considered the core of organelles (30). The mitochondrial function can be mediated by Bcl-2 family proteins (31). The potential role of mitochondria-dependent apoptotic pathway in the apoptotic effect of GAS5 has not been explored.

The present study demonstrated a significant decrease in the expression of GAS5 in EOC tissues, which was associated with clinicopathological parameters. Moreover, the overexpression of GAS5 obviously promoted the apoptosis of ovarian cancer cell lines. Together, these results reveal evidence for apoptosis regulation between lncRNA GAS5 and ovarian cancer, indicating a potential target of diagnosis and gene therapy in the disease.

\section{Materials and methods}

Cell lines and tissue samples. The human ovarian cancer HO8910 (Bioleaf Biotech Co., Ltd., Shanghai, China) and A2780 cells (Chuanbo Biotechnology Co., Ltd., Nanjing, China) were grown in RPMI-1640 and Dulbecco's modified Eagle's medium (DMEM) medium (both from HyClone, Beijing, China), respectively, supplemented with $10 \%$ fetal bovine serum (FBS) (Sijiqing, Zhejiang, China) in a humidified incubator $\left(37^{\circ} \mathrm{C}, 5 \% \mathrm{CO}_{2}\right)$.
Specimens of EOC tissue $(n=60$, without radiation or chemotherapy), normal ovarian epithelial tissues $(n=13)$ and benign ovarian epithelial lesions $(n=10)$ were collected at the Second Affiliated Hospital of Harbin Medical University (China) between March 2012 and April 2014 (median age 55 years, range 37-79). The samples of normal ovarian tissue were collected from hysterosalpingo-oophorectomy following uterine myoma, endometriosis or adenomyosis. Written informed consent was obtained from all participants. The study was approved by the Human Ethnics Committee of the Second Affiliated Hospital of Harbin Medical University (no. 2015-yan-167).

Real-time polymerase chain reaction. Total RNA was extracted from tissues and cell lines using TRIzol reagent (Invitrogen, CA, USA), and RNA purity was identified by optical density (OD) 260/OD $280 \mathrm{~nm}$. The reverse transcription reactions were performed using oligo(dT) primers and a reverse transcriptase kit (Bioneer, Shanghai, China). CDNAs were synthesized from total RNA using the specific primers. The $20-\mu 1$ reactions were incubated on a PCR system for $1 \mathrm{~min}$ at $56^{\circ} \mathrm{C}, 60 \mathrm{~min}$ at $50^{\circ} \mathrm{C}, 5 \mathrm{~min}$ at $95^{\circ} \mathrm{C}$ and then held at $4^{\circ} \mathrm{C}$. Real-time polymerase chain reaction (PCR) was performed with the ABI 7300 real-time PCR system (Applied Biosystems, CA, USA). The assay was carried out in optical tubes at $95^{\circ} \mathrm{C}$ for $5 \mathrm{~min}$, followed by 40 cycles of $95^{\circ} \mathrm{C}$ for $30 \mathrm{sec}$ and $55^{\circ} \mathrm{C}$ for $30 \mathrm{sec}$. For all human ovarian tissues and cell lines, real-time PCR was performed using TaqMan MGB primers and probe specially for human GAS5 (designed by GenePharma, Shanghai, China; forward primer, 3'-CTT CTGGGCTCAAGTGATCCT-5' and reverse primer, 3'-TTG TGCCATGAGACTCCATCAG-5'; probe, CCTCCCAGTG GTCTTT) and eukaryotic 18S rRNA (GenePharma; forward primer, 5'-TTTGACTCAACACGGGAAACC-3' and reverse primer, 5'-CACGGAATCGAGAAAGAGCTATC-3'; probe, CCGGACACGGACAGGATTGACAGAT) served as the endogenous control. All of the real-time PCRs were performed in triplicate. The threshold cycle (CT) data and baselines were determined using auto-settings. The relative quantification of GAS5 expression was calculated using the $2^{-\Delta \Delta \mathrm{Ct}}$ method relative to $18 \mathrm{~s}$ rRNA.

Transfection. To overexpress GAS5, plasmid pCDNA-GAS5 was constructed by Shanghai GenePharma Co., Ltd. of China containing the whole genome sequence of GAS5 (NCBI Reference Sequence: NR_002578.2).

The plasmid carrying pCDNA-GAS5 $(1 \mu \mathrm{g} / \mu \mathrm{l})$ was transfected into ovarian cancer cell lines using Lipofectamine 2000 (Invitrogen); Lipofectamine 2000:pCDNA-GAS5=1:1.4.

Cell proliferation and viability. Cell proliferation and viability of HO8910 and A2780 were evaluated using 3-[4,5-dimethylthiazol-2-yl]-2,5-diphenyl-tetrazolium bromide (MTT) (Amresco LLC, OH, USA) assay. Briefly, after $6 \mathrm{~h}$ transfection with pCDNA-GAS5, $\sim 5 \times 10^{3}$ cells/well were seeded into a 96 -well plate at $37^{\circ} \mathrm{C}$. Each well was repeated six times. After further incubation at different times (24, 48 and $72 \mathrm{~h}$ ), $20 \mu \mathrm{l}$ MTT $(0.5 \mathrm{mg} / \mathrm{ml})$ was added to each well and further incubated for $4 \mathrm{~h}$. Then the medium was removed and dimethylsulfoxide was added to dissolve the MTT formazan crystals. 
The cell viability and proliferation were determined by OD450 value. The experiments were performed three times.

Colony formation assay. Approximately 800 pCDNA-GAS5or empty vector-transfected HO8910 and A2780 cells/wells were placed onto a six-well plate and maintained in a medium containing $10 \%$ FBS, replacing the medium every three days. After 14 days, the colonies were fixed with methanol and stained with $0.5 \%$ crystal violet (Amresco, Shanghai, China). The visible colonies were manually counted. The experiments were performed three times.

Transwell assay. Transwell assays were performed using a Costar chamber (Corning Costar Corp., Cambridge, MA, USA). The bottom chambers were filled with a culture medium containing 10\% FBS. Different samples of tansfected HO8910 or A2780 cells $\left(5 \times 10^{4}\right)$ were suspended into a culture medium without FBS, and then the cells were seeded into the upper chambers. The Transwell chamber containing an $8-\mu \mathrm{m}$ pore size polycarbonate membrane filter was coated either with (for invasion) or without (for migration) Matrigel. After $48 \mathrm{~h}$ of culture at $37^{\circ} \mathrm{C}$, the upper layer of cells were removed before visualization, and the cells on the lower surface were fixed and stained with $0.5 \%$ crystal violet. The cells were counted by Image-Pro Plus 6.0. (Media Cybernetics, Rockville, MD, USA) in five random fields and photographed. The experiments were performed three times.

Terminal deoxynucleotidyl transferase dUTP nick-end labeling (TUNEL). The HO8910 and A2780 cells were transfected with pCDNA-GAS5 or empty vector, and cultured into six-well plates for $48 \mathrm{~h}$. They were then fixed with $4 \%$ paraformaldehyde solution, the apoptotic cells were labeled using the In Situ Cell Death Detection kit (Beyotime, Shanghai, China), the fluorescence was detected using a Nikon Eclipse TE2000-S fluorescence microscope (Nikon, Tokyo, Japan) and counted by Image-Pro Plus 6.0 (Media Cybernetics) in three different experiments, the red fluorescence marked cells were apoptotic cells.

Cell apoptotic analysis. HO8910 and A2780 cells (1-2×10 $)$ were treated with a pcDNA-GAS5 or an empty vector; then placed into six-well plates. After 24-h incubation, the cells were trypsinized and then fixed in $70 \%$ ethanol for $3 \mathrm{~h}$ at $4{ }^{\circ} \mathrm{C}$; $3 \mathrm{~h}$ later, the cells were incubated with propidium iodide (PI) (x20) and RNase A (x50) for 30 min in the dark. Cells were collected and analyzed for apoptosis using a flow cytometer (BD Biosciences, Franklin Lakes, NJ, USA) after PI staining. The results were analyzed by BD Accuri C6 software. The experiments were repeated at least three times.

Mitochondrial membrane potential assay. The JC-1 probe (Beyotime) was performed to measure mitochondrial depolarization in ovarian cancer cells. Briefly, cells $\left(0.5-2 \times 10^{5} / \mathrm{ml}\right)$ were cultured in six-well plates. After treatment for $48 \mathrm{~h}$, they were incubated with an equal volume of a JC-1 staining solution $(5 \mu \mathrm{g} / \mathrm{ml})$ at $37^{\circ} \mathrm{C}$ for $40 \mathrm{~min}$ and rinsed three times with PBS. Mitochondrial membrane potentials were monitored by determining the relative amounts of dual emissions from mitochondrial JC-1 monomers or aggregates using a fluorescent microscope at 488-nm excitation. Mitochondrial depolarization was assessed by the change in the green/red fluorescence intensity ratio. The cells were counted using Image-Pro Plus 6.0 in five random fields.

Western blot analysis. The pCDNA-GAS5- or empty vectortransfected HO8910 and A2780 cells were lysed using a lysis buffer (Beyotime) that contained the phenylmethanesulfonyl fluoride. The protein concentrations were determined by bicinchoninic acid protein assay. The samples $(50 \mu \mathrm{g})$ were electrophoresed on a $10 \%$ sodium dodecylsulfate-polyacrylamide gel electrophoresis and transferred onto nitrocellulose membranes (BioTrance, MI, USA). The membranes were blocked with 0.1\% I-Block (Applied Biosystems) in TBS-T $(0.1 \%$ Tween-20) at room temperature for $1 \mathrm{~h}$, then incubated with specific antibodies at $4^{\circ} \mathrm{C}$ overnight. The membranes were washed with TBS-T (0.1\% Tween-20) and incubated for $1 \mathrm{~h}$ at room temperature with horseradish peroxidaseconjugated secondary antibodies (Bio-Rad Laboratories). Following washing, the specific bands were detected using the enhanced chemiluminescence (Beyotime) chromogenic substrate. The protein expression was analyzed using densitometry (Quantity One software; Bio-Rad, Hercules, CA, USA). $\beta$-actin (ZSGB-BIO, Beijing, China) was used as a control. Additionally, anti-caspase 3 and anti-BAX antibodies were purchased from Santa Cruz Biotechnology (Santa Cruz, CA, USA). Anti-caspase 9 and anti-BAK antibodies were purchased from Beyotime Institute of Biotechnology (Shanghai, China).

Statistical analysis. All statistical analysis was performed with SPSS 17.0 (SPSS, Inc., Chicago, IL, USA). Data are presented as means \pm standard error of mean from at least three independent experiments. Statistical analysis was performed using Chi-square and Student's t-tests, or one-way analysis of variance followed by a post hoc test, where appropriate. Differences were considered to indicate a statistically significant result at $\mathrm{P}<0.05$.

\section{Results}

GAS5 is downregulated in EOC tissues. To investigate whether lncRNA GAS5 controls EOC, real-time PCR was used to examine the GAS5 expression in normal ovarian epithelial tissues, benign ovarian epithelial lesions and EOCs. The GAS5 expression of controls, both normal ovarian epithelial tissues (N) and benign epithelial lesions (B), showed no statistical significance (Fig. 1A). While, there appears to be a significant reduction of GAS5 expression in EOCs (C) compared with normal ovarian epithelial tissues (6.44-fold) (Fig. 1A). Then, the clinicopathological parameters, such as age, differentiation, location, lymph node metastasis and FIGO stage, were analyzed to assess the expression of GAS5 and clinical significance of EOC. As shown in Fig. 1B and C and Table I, samples with lymph node metastasis and advanced FIGO stage had low expression of GAS5. These data indicate that the decreased expression of GAS5 is related to EOC.

The effect of GAS5 on proliferation in ovarian cancer cell lines. With the aim of manipulating the GAS5 expression in 
A

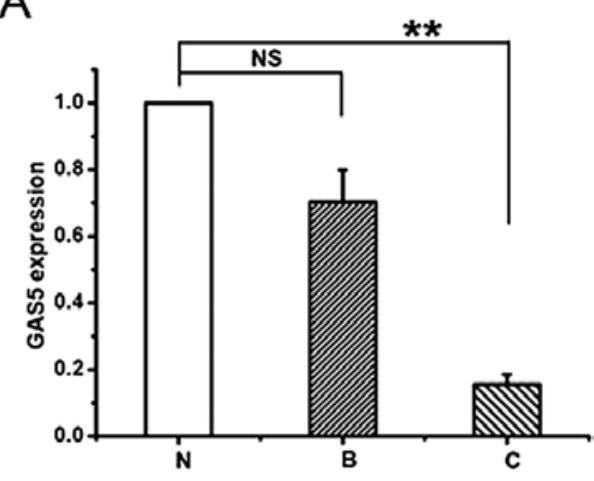

B

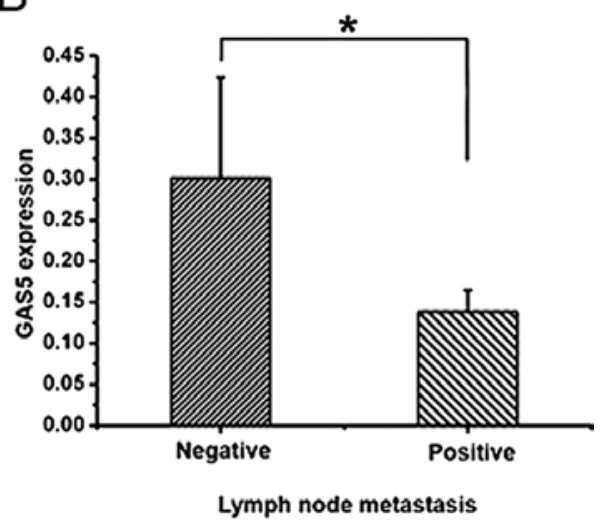

C

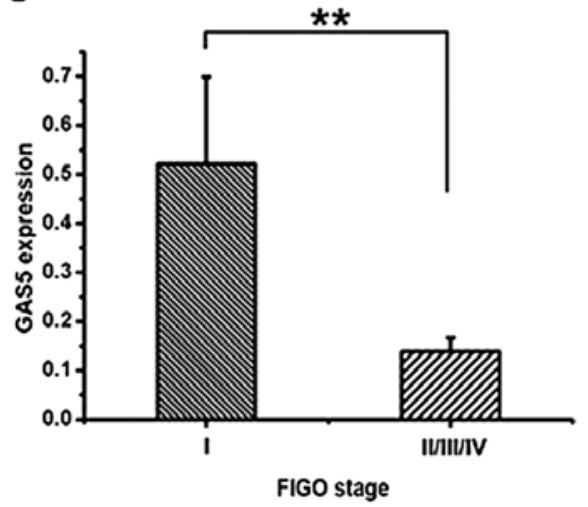

Figure 1. Relative 1ncRNA GAS5 expression in EOC tissues and the clinical significance. (A) Relative expression of 1ncRNA GAS5 was analyzed by real-time PCR in ovarian normal epithelial tissues $(N, n=13)$, ovarian benign epithelial lesions $(B, n=10)$, and epithelial ovarian cancers $(C, n=60)$. LncRNA GAS5 expression was normalized to 18s rRNA expression. The data are presented as a fold-change in the tumor tissues relative to the normal tissues. (B) The correlation between GAS5 and lymph node metastasis. Expression of lncRNA GAS5 was significantly lower in patients with lymph node metastasis than those without lymph node metastasis. (C) The correlation between GAS5 expression and clinical stage. Expression of 1ncRNA GAS5 was significantly lower in patients with an advanced clinical stage than those with an early stage. All values are denoted as means \pm SEM from at least three separate experiments. ${ }^{*} \mathrm{P}<0.05,{ }^{* *} \mathrm{P}<0.01$. ${ }^{*} \mathrm{P}<0.05$ represents negative lymph node metastasis compared with positive lymph node metastasis, ${ }^{* *} \mathrm{P}<0.01$ represents normal ovarian epithelium compared with EOC tissues and FIGO stage of I compared with II/III/IV.

ovarian cancer cells, the pCDNA-GAS5 or an empty vector was transfected into A2780 and HO8910 cells. After 24 h of transfection, the level of GAS5 was well upregulated in A2780
Table I. Correlation between GAS5 expression and clinicopathological parameters of EOC.

\begin{tabular}{|c|c|c|c|c|}
\hline \multirow{2}{*}{$\begin{array}{l}\text { Clinicopathological } \\
\text { parameters }\end{array}$} & \multirow{2}{*}{$\begin{array}{l}\text { No. of } \\
\text { cases }\end{array}$} & \multicolumn{2}{|c|}{$\begin{array}{c}\text { Relative GAS5 } \\
\text { expression }\end{array}$} & \multirow[b]{2}{*}{ P-value } \\
\hline & & Low & High & \\
\hline Age (years) & & & & 0.381 \\
\hline$\leq 50$ & 22 & 13 & 9 & \\
\hline$>50$ & 38 & 18 & 20 & \\
\hline Differentiation & & & & 0.944 \\
\hline Well, moderate & 26 & 14 & 12 & \\
\hline Poor & 34 & 18 & 16 & \\
\hline Location & & & & 0.965 \\
\hline Unilateral & 25 & 13 & 12 & \\
\hline Bilateral & 35 & 18 & 17 & \\
\hline $\begin{array}{l}\text { Lymph node } \\
\text { metastasis }\end{array}$ & & & & $0.025^{\mathrm{b}}$ \\
\hline Positive & 40 & 28 & 12 & \\
\hline Negative & 20 & 8 & 12 & \\
\hline FIGO stage & & & & $0.035^{\mathrm{b}}$ \\
\hline I & 15 & 5 & 10 & \\
\hline II/III/IV & 45 & 29 & 16 & \\
\hline
\end{tabular}

${ }^{\mathrm{a} C h i}$-squared test; ${ }^{\mathrm{b}} \mathrm{P}<0.05$. GAS5, growth arrest-specific transcript 5; EOC, epithelial ovarian cancer.

(74-fold) and HO8910 (63-fold) cells, respectively (Fig. 2A). To ascertain the role of GAS5 in the proliferation of EOC, the overexpression of A2780 and HO8910 cells of GAS5 were analyzed. MTT assay was used to assess the biological role of GAS5 in proliferation. Compared with the cells transfected with empty vector, the ones transfected with pCDNA-GAS5 demonstrated significantly decreased viability (Fig. 2B and C). Besides, it was found that the overexpression of GAS5 greatly weakened the ability of colony forming using the colony formation assay (Fig. 2D-F). The results demonstrated that GAS5 inhibited the proliferation of ovarian cancer cells.

The effect of GAS5 on migration and invasion in ovarian cancer cell lines. Most ovarian cancer patients die of tumor metastasis, and there some research reports concerning the relationship between lncRNAs and neoplastic metastasis $(32,33)$. To study the effect of GAS5 in vitro on migration and invasion of ovarian cancer cell lines, a Costar chamber without (for migration) or with (for invasion) Matrigel was used. The treatment of A2780 and HO8910 cells is the same as described above. Compared with the ones treated with empty vector, the ability of migration and invasion was weakened in GAS5-overexpressed A2780 (Fig. 3A-C) and HO8910 (Fig. 3D and E) cells. Conclusively, GAS5 can inhibit migration and invasion in ovarian cancer cells.

The effect of GAS5 on apoptosis in ovarian cancer cell lines. Apoptosis-resistant phenotype is the major feature of cancer cells (34). To study the role of GAS5 in apoptosis, 

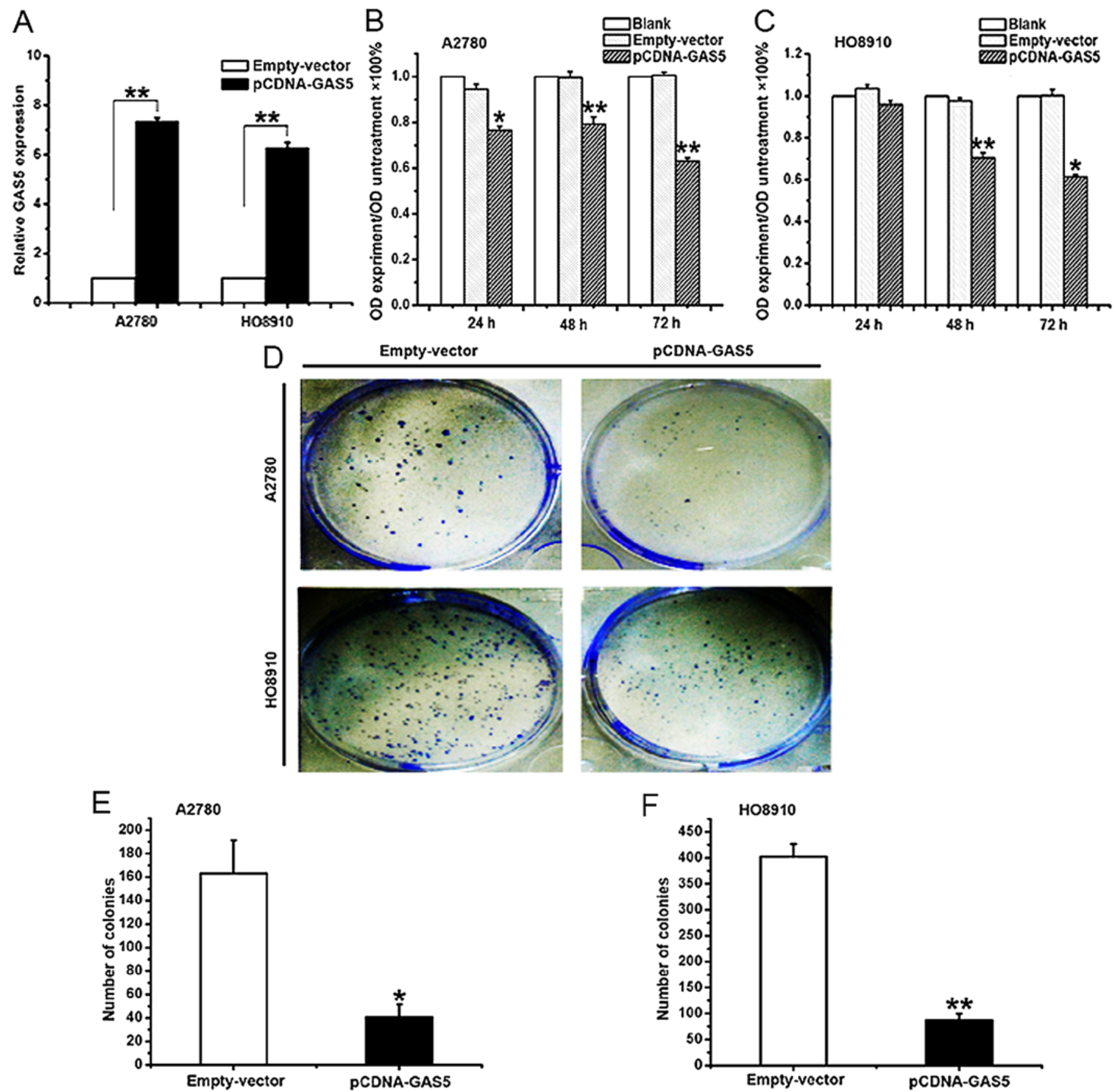

Figure 2. The effect of GAS5 on proliferation in ovarian cancer cells. (A) GAS5 expression, measured by real-time PCR, following the treatment of A2780 and HO8910 cells with pCDNA-GAS5 or empty vector for $24 \mathrm{~h}$. (B) MTT was performed to assess the proliferation of A2780 cells. The cells overexpressed pCDNA-GAS5, transfected with empty vector or untreated, were detected after 24,48 and $72 \mathrm{~h}$, respectively. (C) MTT was applied to examine the proliferation of HO8910 cells. The cells were treated the same way as in A. (D) Colony formation assay was used to evaluate the proliferation of A2780 and HO8910 cells. A2780 and HO8910 cells were transfected with pCDNA-GAS5 or empty vector. The colonies were stained with crystal violet, and were counted viewing with naked eye. (E) Quantitative analysis of the colony content in different groups of A2780 cells. (F) Quantitative analysis of the colonies in different groups of HO8910 cells. The data represent the mean \pm SEM from three independent experiments. ${ }^{*} \mathrm{P}<0.05,{ }^{* * *} \mathrm{P}<0.01,{ }^{*} \mathrm{P}<0.05$ and ${ }^{* * *} \mathrm{P}<0.01$ represent the untreated cells compared with the transfected pCDNA-GAS5 cells.

A2780 and HO8910 cells transfected with pCDNA-GAS5 or empty vector were monitored using flow cytometry. As shown in Fig. 4A-C, ectogenic GAS5 obviously promoted the apoptosis of the cells. Similarly, TUNEL staining showed that the number of apoptotic cells was more in the GAS5overexpressed cells than in the controls (Fig. 4D-F). The above results suggest that GAS5 displays a critical function in pro-apoptosis of ovarian cancer cells.
The effect of GAS5 on mitochondrial depolarization in ovarian cancer cell lines. The statistics previously described demonstrated that GAS5 played a substantial role in apoptosis. The disruption of the mitochondrial membrane potential is an early event of apoptosis. To understand the function of GAS5 on an early stage of apoptosis, JC-1 probe staining was used to detect the effect. The mitochondrial membrane potential of healthy mitochondria, which were 

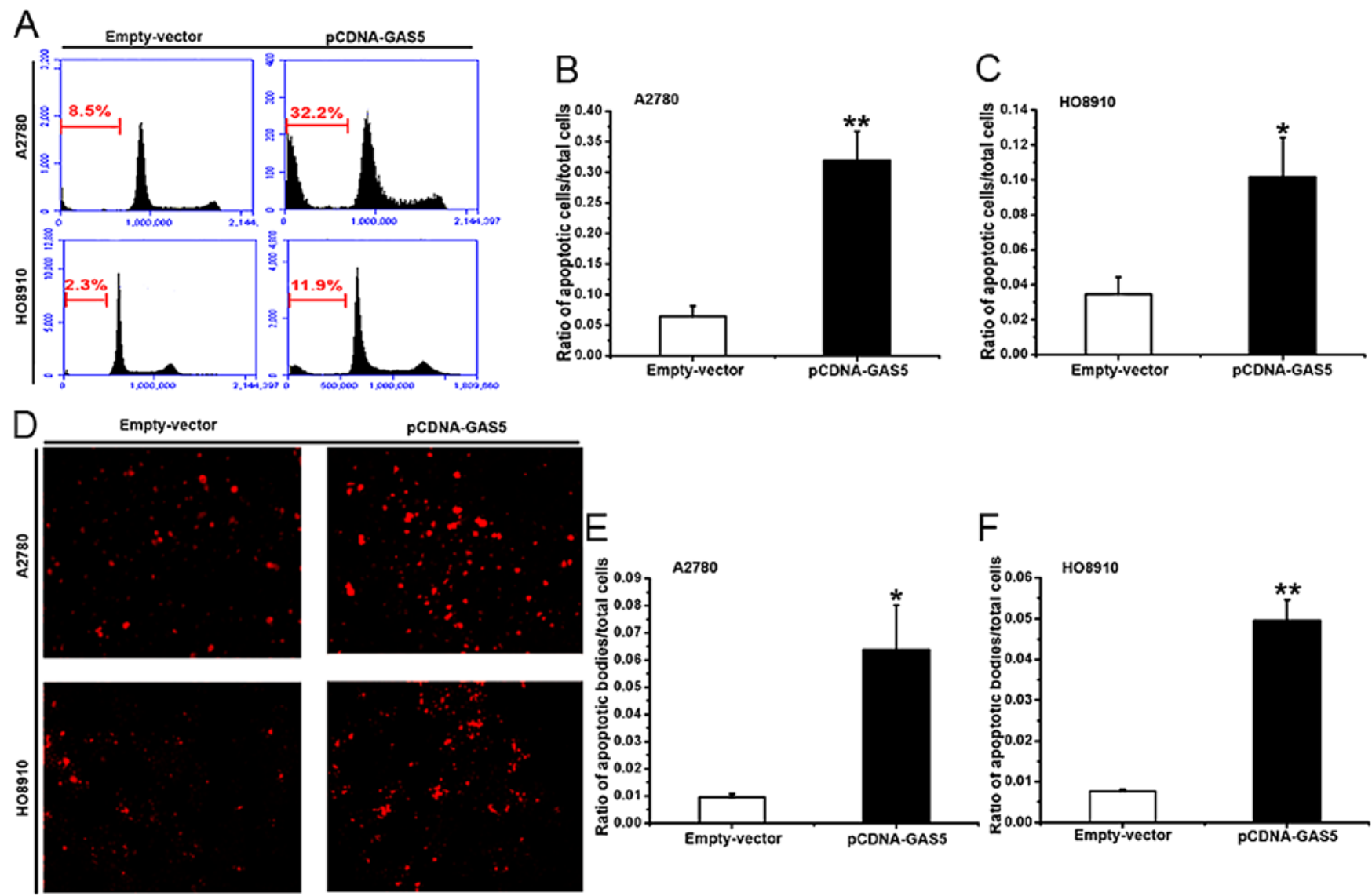

Figure 3. The effect of GAS5 on migration and invasion in ovarian cancer cells. (A) Costar chamber assay was performed to study the influence of GAS5 on migration and invasion of A2780 cells. The cells were treated with pCDNA-GAS5 or empty vector, respectively. After $48 \mathrm{~h}$, the cells on the lower surface of the chamber were stained with crystal violet and photographed by Nikon Eclipse TE2000-S fluorescence microscope (magnification, x10). (B) Quantitative analysis of the migrated cell content in different groups of A2780 cells. (C) Quantitative analysis of the invaded cells content in different groups of A2780 cells. (D) Costar chamber assay was performed to study the influence of GAS5 on migration and invasion of HO8910 cells. The cells were treated the same way as in Fig. 4A. (E) Quantitative analysis of the migrated cells content in different groups of HO8910 cells. (F) Quantitative analysis of the invaded cell content in different groups of HO8910 cells. The amount was counted by Image-Pro Plus 6.0. The data represent the mean \pm SEM from three independent experiments. ${ }^{* * *} \mathrm{P}<0.01$.

detected by JC-1, displayed red fluorescence. When the mitochondrial membrane potential collapsed in apoptotic cells, the JC-1 fluoresced green. As shown in Fig. 5A-C, A2780 and HO8910 cells transfected with pCDNA-GAS5 or empty vector displayed a significant difference. Tumor cell-overexpressed GAS5 showed increased ratios of green/red fluorescence. Thus, these data provide evidence that the action of GAS5 is required for the damage of mitochondrial potential.

The effect of GAS5 on apoptosis pathway in ovarian cancer cell lines. The upregulation of GAS5 in cells was verified to arrest growth (22). The results of flow cytometry (Fig. 4A-C) and TUNEL assay (Fig. 4D-F) demonstrated that GAS5 plays an important role in apoptosis of ovarian cancer cells. The early apoptosis stage was enhanced by GAS5 assessed through JC-1 (Fig. 5A-C). It was, thus, further explored whether GAS5 promoted apoptosis and the underlying pathway.

Pro-apoptotic BAX and BAK is a requisite gateway to mitochondrial dysfunction and death (31), which were used to study the role in GAS5-induced apoptosis of ovarian cancer cells. As shown in Fig. 6A-C, there was an increase in the expression of BAX and BAK in A2780 and HO8910 cells that were overexpressed by the GAS5 gene. Taken together, these results suggest that GAS5 promotes apoptosis potentially by the mitochondrial-mediated apoptosis pathway.

Pro-apoptotic member, BAK, can lead to the release of cytochrome $c$ (35), which can interact with caspase 9 and then activate caspase 3 , contributing to cell apoptosis $(29,36)$. Therefore, cleaved-caspase 3 and cleaved-caspase 9 were also detected. After transfected with pCDNA-GAS5 for $24 \mathrm{~h}$, the protein expression of cleaved-caspase 3 and cleaved-caspase 9 , which were likely to be the critical molecules affected by GAS5, were both significantly higher than the empty-vectortransfected HO8910 and A2780 cells (Fig. 6D-F).

\section{Discussion}

Several important observations were demonstrated in the present study. First, compared with epithelial tissues of normal ovary and benign epithelial ovarian lesions, depressed expression of GAS5 was detected in EOC. Moreover, GAS5 expression appeared to be significantly correlated to lymph node metastasis and FIGO stage of EOC. Second, in vitro, the ability of proliferation, migration and invasion were weakened, while the capability of apoptosis was strengthened by GAS5 

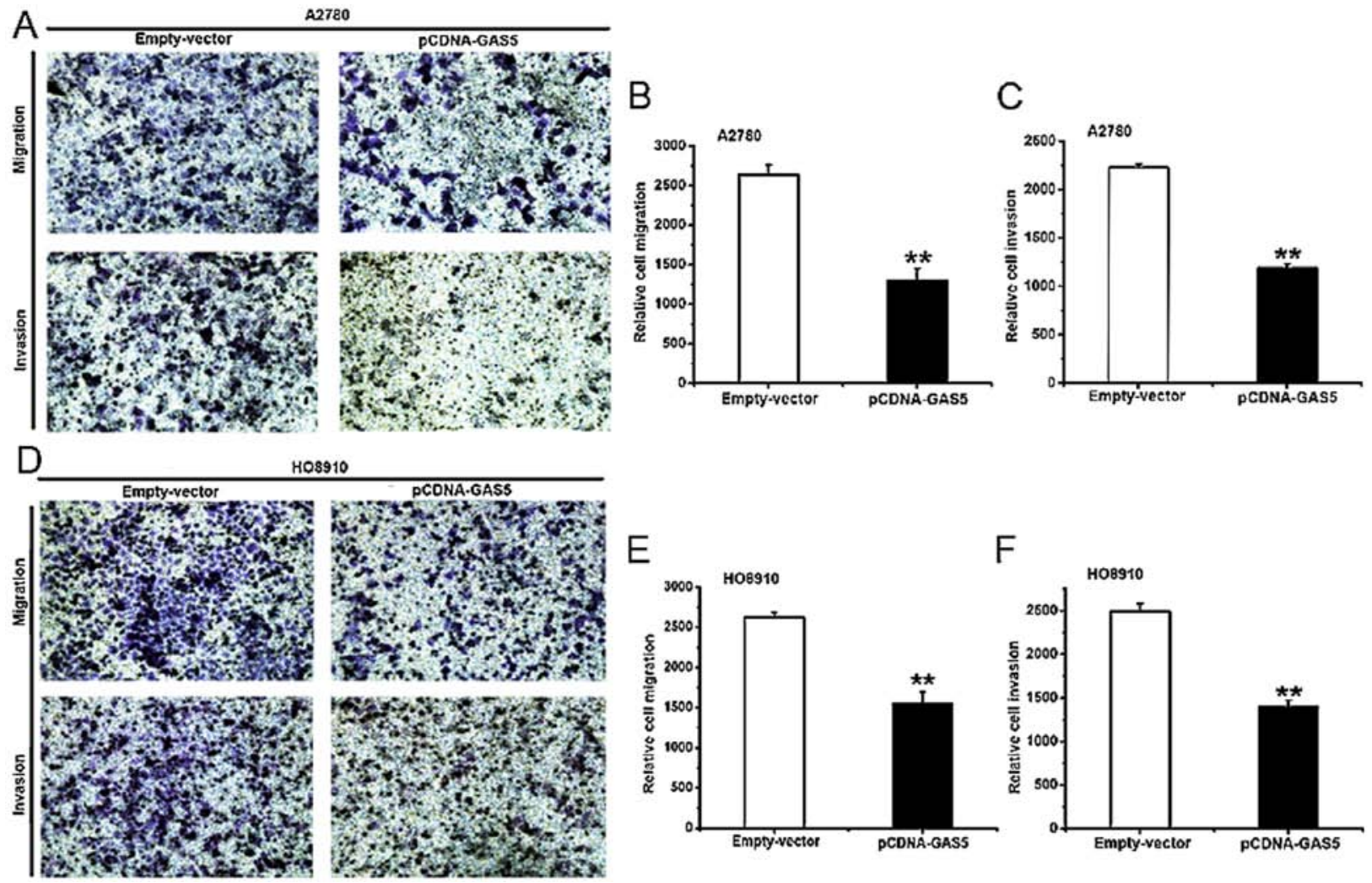

Figure 4. The effect of GAS5 on apoptosis in ovarian cancer cells. Apoptosis of the A2780 and HO8910 cells were examined through flow cytometry using PI staining. The cells were treated with pCDNA-GAS5 or empty vector, respectively. After $48 \mathrm{~h}$, apoptosis was detected. (B) Quantitative analysis of apoptotic cell content in different groups of A2780 cells. (C) Quantitative analysis of the apoptotic cell content in different groups of HO8910 cells. (D) Apoptosis of the A2780 and HO8910 cells were confirmed by TUNEL staining and observed by Nikon Eclipse TE2000-S fluorescence microscope (magnification, x10). The cells were treated the same way as in Fig. 3A. (E) Quantitative analysis of TUNEL-positive cell content in different groups of A2780 cells. (F) Quantitative analysis of TUNEL-positive cell content in different groups of HO8910 cells. The statistics of TUNEL assay were calculated using Image-Pro Plus 6.0. The data represent the mean \pm SEM from three independent experiments. ${ }^{*} \mathrm{P}<0.05,{ }^{* *} \mathrm{P}<0.01$.
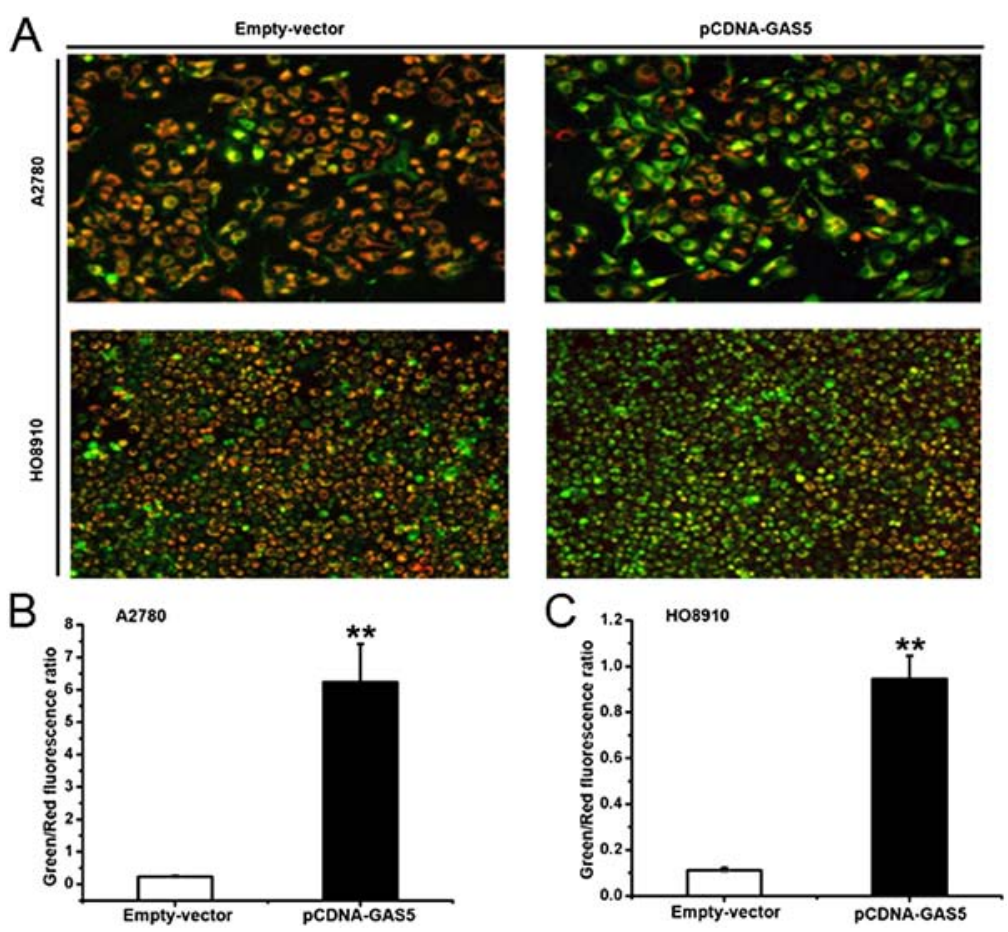

Figure 5. The effect of GAS5 on mitochondrial membrane potential in ovarian cancer cells. (A) Representative images of JC-1 staining in different groups and ovarian cancer cell lines. The cells were treated with pCDNA-GAS5 or empty vector, respectively. After $48 \mathrm{~h}$, the cells were JC-1 probe stained and fluorescent imaged by Nikon Eclipse TE2000-S fluorescence microscope (magnification, x10). (B) Quantitative analysis of the change of mitochondrial red fluorescence to green fluorescence in different groups of A2780 cells. (C) Quantitative analysis of the change of mitochondrial red fluorescence to green fluorescence in different groups of HO8910 cells. The data represent the mean \pm SEM from three independent experiments. ${ }^{* *} \mathrm{P}<0.01$. 

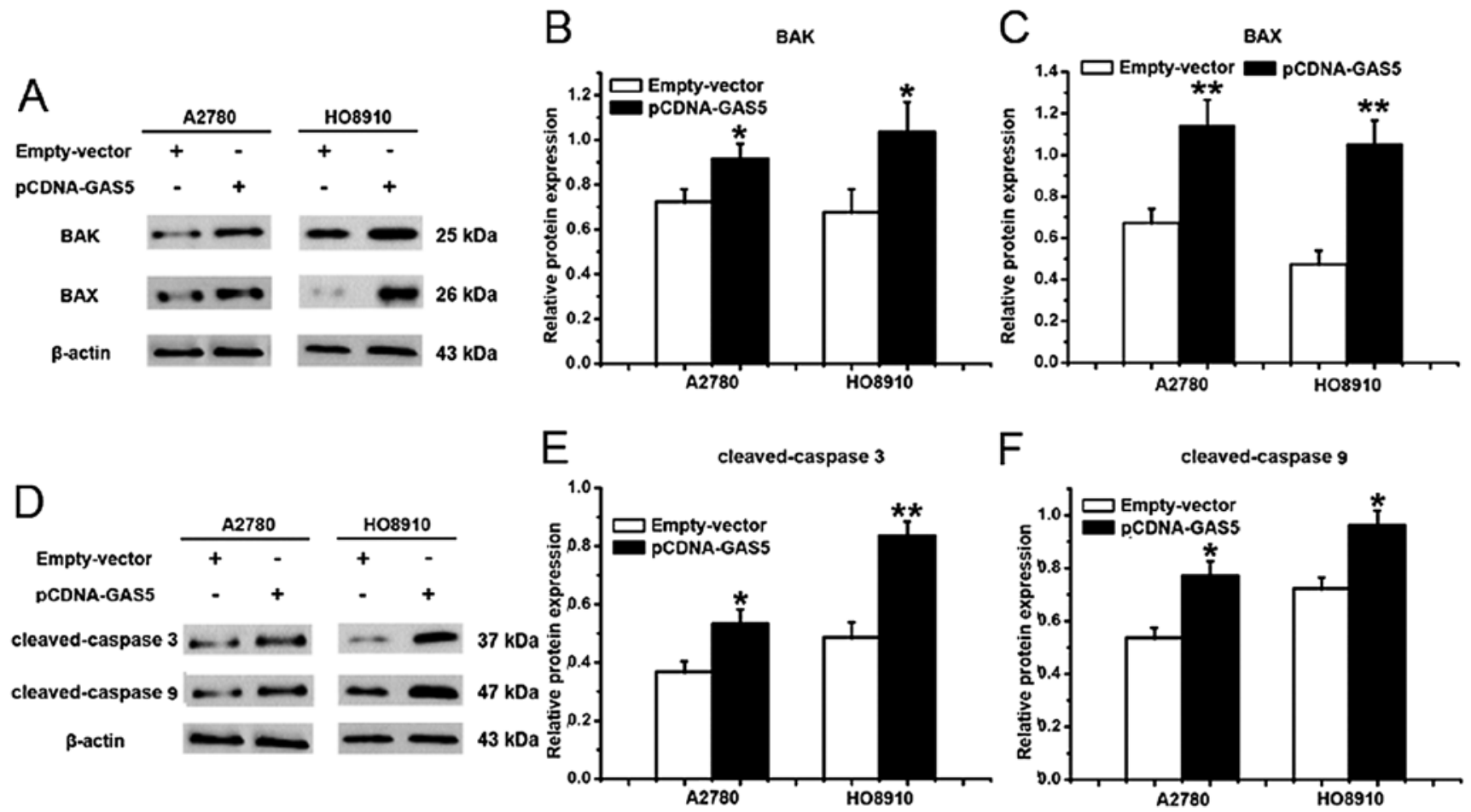

Figure 6. The effect of GAS5 on apoptosis pathway in ovarian cancer cell lines. (A) Expression of BAK and BAX are shown by western blotting. The cells were treated with pCDNA-GAS5 or empty vector, respectively. After $24 \mathrm{~h}$, the cell extracts were analyzed by western blotting with antibody to BAK or BAX. (B) Densitometric analysis of the western blot assays of BAK. (C) Densitometric analysis of the western blot assays of BAX. (D) Expression of cleaved-caspase 3 and cleaved-caspase 9 are presented by western blotting. The cells were treated the same way as in A. The cell extracts were analyzed by western blotting with antibody to cleaved-caspase 3 or cleaved-caspase 9. (E) Densitometric analysis of the western blot assays of cleaved-caspase 3. (F) Densitometric analysis of the western blot assays of cleaved-caspase 9 . All values are denoted as mean \pm SEM from at least three separate experiments. $\beta$-actin protein expression was used as an internal control. ${ }^{*} \mathrm{P}<0.05,{ }^{* *} \mathrm{P}<0.01$.

overexpression. Finally, evidence exists that GAS5 promoted apoptosis of ovarian cancer cells via the mitochondrialdependent apoptosis pathway. The present study provides a novel finding that ovarian cancer is modulated by GAS5.

GAS5 was found downregulated in EOC tissues compared to the normal ovarian epithelium, and lower GAS5 correlated with more transferred lymph nodes and advanced FIGO stage. Consistently, earlier studies showed that GAS5 was downregulated in NSCLC compared with the adjacent normal lung tissues; importantly, lower GAS5 expression correlated with larger tumor size and advanced clinical stage (25). Additionally, findings showed that GAS5 expression was markedly depressed in gastric cancer tissues, and the lower GAS5 mainly appeared in the larger tumor size; an advanced pathologic stage. Moreover, patients with lower GAS5 expression had poorer disease-free survival and overall survival (24). More recently, studies showed that the GAS5 expression was decreased in cervical cancer tissues compared to the adjacent normal tissues, and depressed GAS5 expression was correlated with the advanced FIGO stage, deeper invasion and more lymph node metastasis. Patients with lower GAS5 expression had poorer overall survival (37). Taken together, GAS5 may serve as a tumor suppressor in human tumors.

Cell apoptosis is a complex process that is involved in a variety of regulatory mechanisms and is closely related to tumorigenesis. It has been indicated that GAS5 stimulates apoptosis through significantly different intron or exon composition of these GAS5 transcripts (22). Moreover, the study confirmed that GAS5 leads to the dysfunctional mitochondrial membrane potential. The current study found that GAS5-induced mitochondrial-mediated pro-apoptotic proteins, BAD and BAK (released more from the ovarian cancer cells) were overexpressed by GAS5, indicating that the mitochondrion-modulated apoptosis pathway is required for the pro-apoptotic effect of GAS5 in human ovarian cancer cells.

Mitochondria have been illustrated as the guardian of cell death, and they play a key role in regulating pathways of cell apoptosis $(31,38)$. Besides, the Bcl-2 family proteins and caspases execute a crucial role in the mitochondria-mediated apoptosis pathways. Studies indicate that it is necessary to activate BAX or BAK to initiate mitochondrial dysfunction and cell apoptosis (31). The activation of BAX or BAK has been proposed to result in the formation of a voltage-dependent anion channel-containing pore (39) or permeabilization of mitochondrial membranes (40) to initiate cytochrome $c$ release. Then cytochrome $c$ binds the $\mathrm{C}$-terminal domain of the apoptotic protease-activating factor-1. Later, Apaf1, procaspase 9, and released cytochrome $c$ form the apoptosome that drives the cleaved-caspase 3, one of the most important apoptosis executioners, leading to the mitochondrial dysfunction and cell apoptosis (40).

The present study confirms that GAS5 leads to the dysfunctional mitochondrial membrane potentials in vitro. To further verify the GAS5-induced mitochondria-dependent apoptosis, the expression of BAK, BAX, cleaved-caspase 9 
and cleaved-caspase 3 were evaluated. Consistent with previous studies, significant expression of the proteins was observed after the GAS5 transfection. Taken together, these findings prove that lncRNA GAS5 acts as a tumor-suppressor in human EOC, and the regulating pathway is mitochondrion adjusted. However, there are certain aspects that still need to be resolved: i) more patients samples should be collected to verify the credibility of GAS5 repression function in EOC; ii) the interacting molecular mechanisms and signal pathways on how GAS5 changes the mitochondrion-independent apoptosis should be clarified; and iii) the mechanisms of decreased capabilities of migration and invasion by GAS5 in ovarian cancer cells should be explicated.

In conclusion, the findings of the present study show that GAS5 overexpression can promote apoptosis, inhibit proliferation, and reduce migration and invasion in ovarian cancer cells. In addition, GAS5 expression is lower in EOC tissues than in the normal ovarian epithelium, and the lower expression of GAS5 is correlated to more lymph node metastasis and advanced FIGO stage of EOC, indicating that GAS5 may play a role as a suppressor of tumorigenesis for EOC patients. These findings have major implications for devising a strategy for ovarian cancer treatment.

\section{Acknowledgements}

The authors would like to acknowledge the generous assistance of all the staff of the Key Laboratory of Harbin Medical University (Daqing). The authors also acknowledge the female patients who participated in the present study.

\section{References}

1. Siegel R, Naishadham D and Jemal A: Cancer statistics, 2013. CA Cancer J Clin 63: 11-30, 2013.

2. Naora H: The heterogeneity of epithelial ovarian cancers: Reconciling old and new paradigms. Expert Rev Mol Med 9: $1-12,2007$.

3. Mullany LK, Fan HY, Liu Z, White LD, Marshall A, Gunaratne P, Anderson ML, Creighton CJ, Xin L, Deavers M, et al: Molecular and functional characteristics of ovarian surface epithelial cells transformed by KrasG12D and loss of Pten in a mouse model in vivo. Oncogene 30: 3522-3536, 2011.

4. Quinn BA, Brake T, Hua X, Baxter-Jones K, Litwin S, Ellenson LH and Connolly DC: Induction of ovarian leiomyosarcomas in mice by conditional inactivation of Brcal and $p 53$. PLoS One 4: e8404, 2009.

5. Szabova L, Yin C, Bupp S, Guerin TM, Schlomer JJ, Householder DB, Baran ML, Yi M, Song Y, Sun W, et al: Perturbation of $\mathrm{Rb}, \mathrm{p} 53$, and Brcal or Brca2 cooperate in inducing metastatic serous epithelial ovarian cancer. Cancer Res 72: 4141-4153, 2012.

6. Clark MB, Johnston RL, Inostroza-Ponta M, Fox AH, Fortini E, Moscato P, Dinger ME and Mattick JS: Genome-wide analysis of long noncoding RNA stability. Genome Res 22: 885-898, 2012.

7. Gutschner T and Diederichs S: The hallmarks of cancer: A long non-coding RNA point of view. RNA Biol 9: 703-719, 2012.

8. Alaiyan B, Ilyayev N, Stojadinovic A, Izadjoo M, Roistacher M, Pavlov V, Tzivin V, Halle D, Pan H, Trink B, et al: Differential expression of colon cancer associated transcript1 (CCAT1) along the colonic adenoma-carcinoma sequence. BMC Cancer 13: 196, 2013.

9. Ling H, Spizzo R, Atlasi Y, Nicoloso M, Shimizu M, Redis RS, Nishida N, Gafa R, Song J, Guo Z, et al: CCAT2, a novel noncoding RNA mapping to 8q24, underlies metastatic progression and chromosomal instability in colon cancer. Genome Res 23: 1446-1461, 2013.
10. Xiang JF, Yin QF, Chen T, Zhang Y, Zhang XO, Wu Z, Zhang S, Wang HB, Ge J, Lu X, et al: Human colorectal cancer-specific $C C A T 1-L$ lncRNA regulates long-range chromatin interactions at the MYC locus. Cell Res 24: 513-531, 2014.

11. Tee AE, Ling D, Nelson C, Atmadibrata B, Dinger ME, Xu N, Mizukami T, Liu PY, Liu B, Cheung B, et al: The histone demethylase JMJD1A induces cell migration and invasion by up-regulating the expression of the long noncoding RNA MALAT1. Oncotarget 5: 1793-1804, 2014.

12. Gutschner T, Hämmerle $\mathrm{M}$ and Diederichs S: MALAT1 - a paradigm for long noncoding RNA function in cancer. $\mathrm{J}$ Mol Med 91: 791-801, 2013.

13. Gutschner T, Hammerle M, Eissmann M, Hsu J, Kim Y, Hung G, Revenko A, Arun G, Stentrup M, Gross M, et al: The noncoding RNA MALAT1 is a critical regulator of the metastasis phenotype of lung cancer cells. Cancer Res 73: 1180-1189, 2013.

14. Brown JA, Bulkley D, Wang J, Valenstein ML, Yario TA, Steitz TA and Steitz JA: Structural insights into the stabilization of MALAT1 noncoding RNA by a bipartite triple helix. Nat Struct Mol Biol 21: 633-640, 2014

15. Raho G, Barone V, Rossi D, Philipson L and Sorrentino V: The gas 5 gene shows four alternative splicing patterns without coding for a protein. Gene 256: 13-17, 2000.

16. Smith CM and Steitz JA: Classification of gas 5 as a multismall-nucleolar-RNA (snoRNA) host gene and a member of the 5'-terminal oligopyrimidine gene family reveals common features of snoRNA host genes. Mol Cell Biol 18: 6897-6909, 1998.

17. Kino T, Hurt DE, Ichijo T, Nader N and Chrousos GP: Noncoding RNA gas 5 is a growth arrest- and starvation-associated repressor of the glucocorticoid receptor. Sci Signal 3: ra8, 2010.

18. Coccia EM, Cicala C, Charlesworth A, Ciccarelli C, Rossi GB, Philipson L and Sorrentino V: Regulation and expression of a growth arrest-specific gene (gas5) during growth, differentiation, and development. Mol Cell Biol 12: 3514-3521, 1992.

19. Fingar DC and Blenis J: Target of rapamycin (TOR): An integrator of nutrient and growth factor signals and coordinator of cell growth and cell cycle progression. Oncogene 23: 3151-3171, 2004.

20. Zhang Z, Zhu Z, Watabe K, Zhang X, Bai C, Xu M, Wu F and Mo YY: Negative regulation of lncRNA GAS5 by miR-21. Cell Death Differ 20: 1558-1568, 2013.

21. Pickard MR, Mourtada-Maarabouni M and Williams GT: Long non-coding RNA GAS5 regulates apoptosis in prostate cancer cell lines. Biochim Biophys Acta 1832: 1613-1623, 2013.

22. Mourtada-Maarabouni M, Pickard MR, Hedge VL, Farzaneh F and Williams GT: GAS5, a non-protein-coding RNA, controls apoptosis and is downregulated in breast cancer. Oncogene 28: 195-208, 2009.

23. Renganathan A, Kresoja-Rakic J, Echeverry N, Ziltener G, Vrugt B, Opitz I, Stahel RA and Felley-Bosco E: GAS5 long non-coding RNA in malignant pleural mesothelioma. Mol Cancer 13: 119, 2014.

24. Sun M, Jin FY, Xia R, Kong R, Li J, Xu T, Liu Y, Zhang E, Liu X and De W: Decreased expression of long noncoding RNA GAS5 indicates a poor prognosis and promotes cell proliferation in gastric cancer. BMC Cancer 14: 319, 2014.

25. Xuefei Shi MS, Liu H, Yao Y, Kong R, Chen F and Song Y: A critical role for the long non-coding RNA GAS5 in proliferation and apoptosis in non-small-cell lung cancer. Mol Carcinog 54 (Suppl 1): E1-E12, 2015.

26. Hay N and Sonenberg N: Upstream and downstream of mTOR. Genes Dev 18: 1926-1945, 2004.

27. Huang FJ and Chan WH: Effects of ochratoxin a on mouse oocyte maturation and fertilization, and apoptosis during fetal development. Environ Toxicol: Dec 15, 2014 (Epub ahead of print).

28. Danial NN and Korsmeyer SJ: Cell death: Critical control points. Cell 116: 205-219, 2004.

29. Hengartner MO: The biochemistry of apoptosis. Nature 407: 770-776, 2000

30. Crow MTMK, Nam YJ and Kitsis RN: The mitochondrial death pathway and cardiac myocyte apoptosis. Circ Res 95: 957-970, 2004.

31. Wei MC, Zong WX, Cheng EH, Lindsten T, Panoutsakopoulou V, Ross AJ, Roth KA, MacGregor GR, Thompson CB and Korsmeyer SJ: Proapoptotic BAX and BAK: A requisite gateway to mitochondrial dysfunction and death. Science 292: 727-730, 2001. 
32. Guttman M and Rinn JL: Modular regulatory principles of large non-coding RNAs. Nature 482: 339-346, 2012.

33. Gupta RA, Shah N, Wang KC, Kim J, Horlings HM, Wong DJ, Tsai MC, Hung T, Argani P, Rinn JL, et al: Long non-coding RNA HOTAIR reprograms chromatin state to promote cancer metastasis. Nature 464: 1071-1076, 2010.

34. Meier P, Finch A and Evan G: Apoptosis in development. Nature 407: 796-801, 2000

35. Vyssokikh MY,Zorova L, Zorov D, Heimlich G, Jürgensmeier JM and Brdiczka D: Bax releases cytochrome $c$ preferentially from a complex between porin and adenine nucleotide translocator. Hexokinase activity suppresses this effect. Mol Biol Rep 29: 93-96, 2002.

36. Slee EA, Harte MT, Kluck RM, Wolf BB, Casiano CA, Newmeyer DD, Wang HG, Reed JC, Nicholson DW, Alnemri ES, et al: Ordering the cytochrome $c$-initiated caspase cascade: Hierarchical activation of caspases-2, $-3,-6,-7,-8$, and -10 in a caspase-9-dependent manner. J Cell Biol 144: 281-292, 1999.
37. Cao S, Liu W, Li F, Zhao W and Qin C: Decreased expression of lncRNA GAS5 predicts a poor prognosis in cervical cancer. Int J Clin Exp Pathol 7: 6776-6783, 2014.

38. Green DR and Kroemer G: The pathophysiology of mitochondrial cell death. Science 305: 626-629, 2004.

39. Shimizu S, Narita M and Tsujimoto Y: Bcl-2 family proteins regulate the release of apoptogenic cytochrome $c$ by the mitochondrial channel VDAC. Nature 399: 483-487, 1999.

40. Kluck RM, Esposti MD, Perkins G, Renken C, Kuwana T, Bossy-Wetzel E, Goldberg M, Allen T, Barber MJ, Green DR, et al: Pro-apoptotic proteins, Bid and Bax, cause a limited permeabilization of the mitochondrial outer membrane that is enhanced by cytosol. J Cell Biol 147: 809-822, 1999. 